\title{
Histopathological correlation of resected appendicectomy specimens - a five year study in a tertiary care centre in Kerala
}

\author{
Navya Narayanan $O^{1}$, Siyad P. ${ }^{2}$, John A. E. ${ }^{3}$ \\ ${ }^{1}$ Dr. Navya Narayanan O., Associate Professor, ${ }^{2}$ Dr. Siyad P., Assistant Professor, ${ }^{3}$ Dr. Annu Elizabeth John, Assistant \\ Professor; all authors are attached with Department of Pathology, Sree Narayana Institute of Medical Sciences Chalaka, \\ Ernakulam, Kerala, India.
}

Corresponding Author: Dr. Navya Narayanan O., Associate Professor Pathology, Sree Narayana Institute of Medical Sciences, Chalaka, Ernakulam, Kerala. India. E-mail: navyanarayano@gmail.com

\begin{abstract}
Background: Acute Appendicitis is one of the common cause of acute abdomen leading to appendectomy which is one of the most frequently performed operations all over the world. Being a common surgery, appendicectomy specimens contribute a major part of routine specimens in any pathology laboratory. a large number of medical and surgical diseases can closely mimic appendicitis leading to negative appendicectomy. Objectives: To find out the age, sex related incidence and different histopathological lesions seen in resected appendicectomy specimens in a tertiary care centre in south India. We also tried to find out negative appendicectomy rate. Materials and Method: This is a retrospective study conducted in the department of pathology, Sree Narayana Institute of Medical Sciences, Kerala. We analyzed the histopathology reports of those patients who had undergone appendicectomy in our hospital during last five year period (January 2014- December 2018). Results: During the study period of five years, 597 appendectomies were done. The mean age of the patients undergoing appendicectomy was found to be 25-35 years. Most of the patients were adults between 21-30 years and number of male patients (386) was more compared to females. Acute appendicectomy specimens showed the presence of fecoliths, gangrene, serositis, worms, lymphoidhyperplasia etc. The negative appendectomy rate was 5.6\%. Conclusions: Detailed histopathological examination is always recommended in appendicectomy specimens not only to confirm the diagnosis, but also to rule outincidental pathologies their by leading tobetter patient outcome.
\end{abstract}

Keywords: Appendix, Resection, Negative

\section{Introduction}

Acute Appendicitis is one of thecommon cause of acute abdomen leading to appendectomy which is one of the most frequently performed operations all over the world $[1,2]$. While in United States, 250,000 cases of appendicitis are reported annually, incidence is much lower in afro Asian countries probably due to dietary actors [3]. Clinically acute appendicitis presents with fever and pain near the umbilicus which moves toward the lower-right side of the abdomen accompanied by nausea, vomiting, loss of appetite etc.

The diagnosis of appendicitis is made according to the clinical features and surgical removal/ appendectomy is the offered treatment of choice. Complications of acute appendicitis include perforation peritonitis, gangrene and sepsis [4]. The approximate lifetime risk for

Manuscript received: $2^{\text {nd }}$ May 2019

Reviewed: $10^{\text {th }}$ May 2019

Author Corrected: $17^{\text {th }}$ May 2019

Accepted for Publication: $22^{\text {nd }}$ May 2019 developing acute appendicitis in a person is found to be around 7-9 \% with peak incidence between 10-30 years of age. It is seen that incidence of acute appendicitis varies among different age groups and population. This is thoughtto be caused by different environmental and behavioral factors like general hygiene, parasite and enteric infection leading to lymphoid hyper plasiain GI tract etc. The Right iliac fossa pain can occur due to different pathologies especially in females leading to diagnostic difficulties resulting in negative appendectomies. Histological examination of resected appendix specimens are routinely done in our hospital, so we decidedto correlate the histopathological findings with theclinical diagnosis of appendicitis.

\section{Objectives}

To find out the age, sex related incidence anddifferent histopathological lesions seen in resected appendicestomy specimens in a tertiary care centre in south India. 


\section{Materials andMethods}

Studysetting: Department of Pathology, Sree Narayana Institute of Medical Sciences, Kerala.

Type of study: A retrospective study.

Sampling methods: Convenience sampling

Sample collection: We collected the histopathology reports of those patients who had undergone appendicectomy in our hospital during last five year period between January 2014- December 2018 from our computer records. The other relevant data of these patients are collected from medical records. The collected information include age, sex, demographic features, investigation findings and common clinical presentation. Histopathologically acute appendicitis is diagnosed when neutrophils are seen in the muscle layer. We also tried to find outnegative appendectomy

\section{Original Research Article}

rate, which is defined as a post operative appendix specimen for suspected appendicitis that was however microscopically normal on histopathological examination without evidence of inflammation, tumor and parasite infestation.

Inclusion criteria: All patients who had undergone appendicectomy in our hospitalduring last five year period between January 2014- December 2018

Exclusion criteria: We excluded those patients in whom appendicectomy is done as a part of surgery done for malignancy of ileocecal area

Statistical methods: The collected data were analyzed by SPSS version 20 and applied simple statistical tests

Ethical consideration \& permission: explained consent was taken before surgery.

\section{Results}

During the study period of five years, 597 appendectomies were done in our hospital. The mean age of the patients undergoing appendicectomy was found to be 25-35 years (5-75 years). Most of the patients were adults between 21-30 years and number of male patients (386) was more compared to females (Table 1,2)

Table-1: Distribution of patients according to sex.

\begin{tabular}{|c|c|}
\hline Sex & Number \\
\hline Male & 386 \\
\hline Female & 211 \\
\hline
\end{tabular}

Table-2: Distribution of patients according to age range [n (\%)]

\begin{tabular}{|c|c|}
\hline Age & Number \\
\hline $17-20 y$ & 116 \\
\hline $21-30$ & 241 \\
\hline $31-40$ & 89 \\
\hline $41-50$ & 81 \\
\hline $51-60$ & 58 \\
\hline$>60$ & 12 \\
\hline Total & $\mathbf{5 9 7}$ \\
\hline
\end{tabular}

Table-3: Distribution of patients according to histopathologic findings.

\begin{tabular}{|c|c|}
\hline Histopathologic findings & Number \\
\hline Acute appendicitis with serositis & $371(62.1 \%)$ \\
\hline Gangrene with perforation & $73(12.2 \%)$ \\
\hline Obliterativeappendicitis & $37(6.1 \%)$ \\
\hline Parasites & $6(1 \%)$ \\
\hline Lymphoidhyperplasia & $59(9.8 \%)$ \\
\hline Granulomatous inflammation & $4(.67 \%)$ \\
\hline Mucocele & $8(1.3 \%)$ \\
\hline Mucinous cystadenoma & $2(.3 \%)$ \\
\hline Appendiceal tumors & $3(.5 \%)$ \\
\hline Negative appendicectomy & $34(5.6 \%)$ \\
\hline
\end{tabular}




\section{Original Research Article}

Based on the histopathologic findings, specimens were divided into two groups; positive for features of acute appendicitis or negative forfeatures. Acute appendicectomy specimens showed the presence of fecoliths, gangrene, serositis, worms, lymphoid hyperplasia, granulomatous inflammation, mucocele, mucinous cystadenoma, or appendiceal tumors (Table 3). Negative specimens were found to bemicroscopically normal, with no evidence of inflammation or appendiceal tumors. The negative appendectomy rate was $5.6 \%$ the female sex accounted for $67 \%$ of the negative appendectomies

\section{Discussion}

Resection of appendix foracute appendicitis is one of the most common surgical interventions performed worldwide $[1,2]$. The incidence of acute appendicitis is found to roughly parallels the development of lymphoid tissue with peak time between 10 - 30 years. The sex ratio in acute appendicitis is equal before puberty, but by $15-25$ years of old it has seen shifted to 2:1 in favor of men. Various studies showed the overall incidence of acute appendicitis in life time is approximately is $7.0 \%$ with $8.6 \%$ for men and $6.7 \%$ for women $[5,6]$.

The acute appendicitis is diagnosed by combined evaluation of patient's history, investigation findings and surgeon's subjective judgment. Various other clinical conditions mimicking acute appendicitis can be found out by abdominal ultra sonography (US) or computed tomography (CT). Abdominal ultrasound is a cost-efficient and valuable investigation in the diagnosis of doubtful cases of appendicitis [7]. Still with all these investigation modalities, negative histopathological diagnosis can occurin $9.2 \%$ cases and this is found to be higher among females in reproductive age group. The rate of negative appendectomy found in ourstudy (5.6\%) is low compared to other similar studies $[5,6,8]$.

Obstruction of the lumen of the appendix caused by fecoliths or lymphoid hyperplasia is thought to be the most important factor in the pathogenesis of acute appendicitis. Extension of inflammation through the walls of appendix will lead to serositis. Persistent ischemia can lead to gangrenous necrosis followed by perforation peritonitis (figure 1,2)

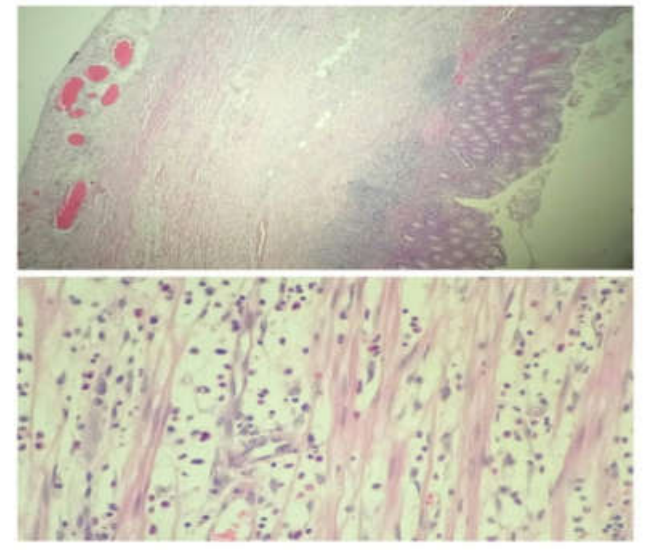

Figure-1: Acute appendicitis showing infiltration by neutrophils, eosinophils and serositis (lowpower (upper) and highpower (lower) appearance H \& E

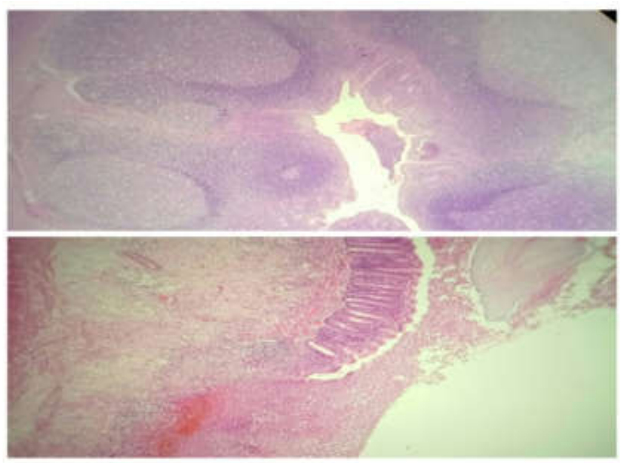

Figure-2: Appendix showing lymphofollicular hyperplasia (upper) and gangrenous perforation (lower) 


\section{Original Research Article}

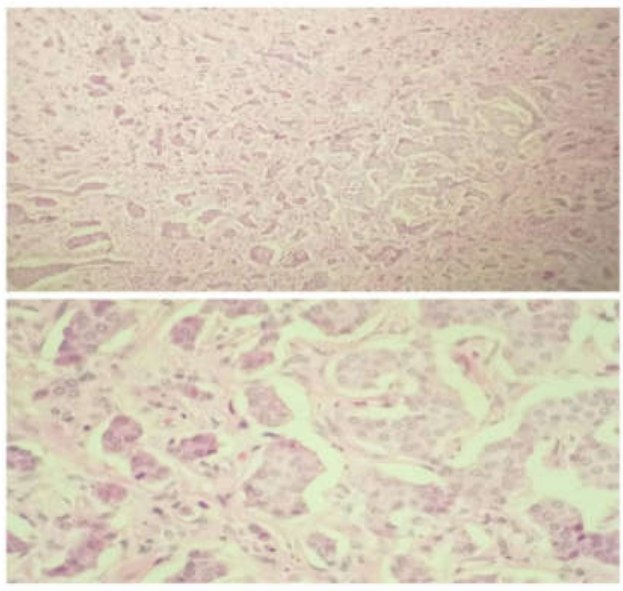

Figure-3: Carcinoid tumor ofappendix showing infiltration bynests of neuroendocrine cells

About $6.1 \%$ of resected appendix show obliteration of the lumen by fibrous tissue. This condition is named as, neurogenic appendicopathy/ appendiceal neuroma, develop secondary to hyperplasia of neuroendocrine cells, due to chronic inflammation [9].

Carcinoid tumor accounts for the most common primary malignant lesion of the appendix which accounts for $60 \%$ of all appendiceal tumors (figure 3) Usually Carcinoidsare found incidentally during surgery [10]. Most of the carcinoid tumors are found to be less than $1 \mathrm{~cm}$ and are seen located at the tip. These small tumors are usually benign, with a near zero rate of calculated risk of metastasis [11]. In our scenario the incidence of appendiceal carcinoidis found to be.5\%. Therefore, even when grossly appendectomy specimens appearnormal, histopathologic examination is mandatory. Since early detection and treatment of malignancy will definitely leadto improve patient treatment results by revealing an early stage disease.

The parasitic infection by Enterobiusvermicularis /pinworms is very common worldwide and it is found to affect up to 200 million people worldwide. The association of E vermicularisin acute appendectomy specimens have ranged from $0.2 \%$ to $41.8 \%$ [12]. We also have similar incidence (1\%) of pin worm infection in our studies. Other parasites like $\mathrm{T}$ saginata, or Entamobahistolitica, are also seen infesting appendix leading to clinical symptoms. After incidental detection of parasites in appendectomy specimens, anti-helminth treatment should be started.

Granulomatous appendicitis is a rare diagnosis (1.3\% to $2.3 \%$ in developing countries) which may be caused by various infectious and non infectious factors [13,14]. Diagnostic criteria of granulomatous appendicitis include presence of granulomatous inflammation with fissuring-type ulcers and transmural lymphoid aggregates. Systemic diseases like Crohn's disease and sarcoidosis, should be excluded and in countries where tuberculosis is endemic detailed testing should be done to ruleout this infectious condition also. We extensively examined our patients, but no evidence supporting these diagnoses were found. So a diagnosis of granulomatous appendicitis was made in 4 cases $(67 \%)$.

Mucocele of appendixare often asymptomatic conditionand are usually discovered incidentally during appendectomy which was seen in 8 cases. Mucocele of appendix is an obstructive dilatation resulting from intraluminal accumulation of mucoid material [15]. The reported incidence of this condition in appendectomy specimensis found to be $0.2 \%$ to $0.7 \%$. Histopathologically it may be caused by are tention cyst. Or other conditions likemucosal hyperplasia, mucinous cyst adenoma, or amucinous cystadenocarcinoma [16]. Even thoughstudies show endometriosis and diverticular disease can affect appendix, we haven’tsimilar experience $[17,18]$.

Although in most of the cases, clinical features of appendicitis is classical with leading symptoms and signs, a large number of medical and surgical diseases can closely mimic appendicitis. Meckel's diverticulitis, pelvic inflammatory disease, cholecystis is, perforated duodenal ulcer, ectopic pregnancy, kidney diseases, right-sided diverticulitis, and Crohn's can produce similar clinical features. This will result in reaching a false diagnosis in a large number of patients especially in females leading to unwanted removal of the normal appendix. Our study showed a low negative appendicectomy rate which is within the acceptable range but showed similar trend by being high among females. 


\section{Original Research Article}

\section{Conclusion}

Being a common surgery, Appendectomy specimens contribute a major part of routine specimens in any pathology laboratory. Detailed histopathological examination is always recommended not only to confirm the diagnosis, but also to rule out incidental pathologies leading to better patient outcome.

We can also find out negative appendectomy rate and try to lower it by combined clinical assessment and usage of appropriate diagnostic imaging modalities.

Acknowledgment: I express my sincere gratitude to the second and third author in helping in data collection. I am also greatful for all teaching and non-teaching staff in pathology department or their support during my study period.

Scope of the study: This is one of the first study conducted about the common conditions leading appendicectomy in Kerala population. This study adds the knowledge about common causes of appendicectomy and gives us an idea about the negative appendicectomy rate, even though low it can be further reduced by clinicoradiological correlation.

Findings: Nil; Conflict of Interest: None initiated Permission from IRB: Yes

\section{References}

1.Marudanayagam R, Williams GT, Rees BI. Review of the pathological results of 2660 appendicectomy specimens. J Gastroenterol. 2006 Aug;41(8):745-9. DOI:10.1007/s00535-006-1855-5

2. Akbulut S, Tas M, Sogutcu N, et al. Unusual histopathological findings in appendectomy specimens: a retrospective analysis and literature review. World $\mathrm{J}$ Gastroenterol. 2011 Apr 21;17(15):1961-70. doi: 10.3748/wjg.v17.i15.1961.

3. Lohar HP. Epidemiological aspects of appendicitis in a rural setup. Medical JDY Univ 2014;7(6):753-7.

4. Maitra A, Abbas AK. Robbins and Cotran. Pathologic Basis of Disease. 7th ed. New Delhi: Elsevier; 2004. The female genital system; p. 1169-70.

5. Seetahal SA, Bolorunduro OB, Sookdeo TC, Oyetunji TA, Greene WR, Frederick W. Negative appendectomy: a 10-year review of a nationally representative sample. Am J Surg 2011; 201 (4): 433-437.
6. Khairy G. Acute appendicitis: is removal of a normal appendix still existing and can we reduce its rate? Saudi J Gastroenterol. 2009 Jul-Sep;15(3):167-70. doi: 10. 4103/1319-3767.51367.

7. Jain RK, Jain $M$, Rajak CL, Mukherjee S, Bhattacharyya PP, Shah MR. Imaging in acute appendicitis: a review. Indian J Radiol Imaging 2006;16 (4): 523-532

8. Chandrasegaram MD, Rothwell LA, An EI, et al. Pathologies of the appendix: a 10-year review of 4670 appendicectomy specimens. ANZ J Surg. 2012 Nov;82 (11): 844-7. doi: 10.1111/j.1445-2197.2012. 06185 .x. Epub 2012 Aug 24.

9. Gupta K, Solanki A, Vasishta RK. Appendiceal neuroma: report of an elusive neuroma. Trop Gastroenterol. 2011 Oct-Dec;32(4):332-3.

10. In't Hof KH, van der Wal HC, Kazemier G, et al. Carcinoid tumour of the appendix: an analysis of 1,485 consecutive emergency appendectomies. J Gastrointest Surg. 2008 Aug;12(8):1436-8. doi: 10.1007/s11605008-0545-4. Epub 2008 Jun 3.

11. Shapiro R, Eldar S, Sadot E, et al. Appendiceal carcinoid at a large tertiary center: pathologic findings and long-term follow-up evaluation. Am J Surg. 2011 Jun; 201 (6): 805-8. doi: 10.1016/j. amjsurg. 2010.04. 016 .

12. Sartorelli AC, da Silva MG, Rodrigues MA, da Silva RJ. Appendiceal taeniasis presenting like acute appendicitis. Parasitol Res 2005;97(2):171-172

13. Tucker ON, Healy V, Jeffers M, et al. Granulomatous appendicitis. Surgeon. 2003 Oct;1(5):286-9.

14. Shivakumar P, Shanmugam RP, Mani CS. Idiopathic granulomatous appendicitis: a rare appendicular pseudo tumor. Trop Gastroenterol. 2010 Apr-Jun; 31(2):130-1.

15. Demetrashvili Z, Chkhaidze M, Khutsishvili K, et al. Mucocele of the appendix: case report and review of literature. Int Surg. 2012 Jul-Sep;97(3):266-9. doi: 10. 9738/CC139.1.

16. Dixit A, Robertson JH, Mudan SS, Akle C. Appendiceal mucocoeles and pseudomyxoma peritonei. World J Gastroenterol 2007; 13(16): 23812384 . 
17. Coulier B, Pierard F, Malbecq S. Appendicular diverticulitis in an Amyand's hernia. JBR-BTR. 2010 Mar-Apr;93(2):114.

18. Emre A, Akbulut S, Yilmaz M, Bozdag Z. An unusual cause of acute appendicitis: appendiceal endometriosis. Int J Surg Case Rep 2012; 4 (1):54-57

19. Mohit Kumar Joshi,Richa Joshi, Shaan E. Alam, Sarla Agarwal, and Sunil Kumar. Negative

\section{Original Research Article}

Appendectomy: an Audit of Resident-Performed Surgery. How Can Its Incidence Be Minimized?Indian J Surg. 2015 Dec; 77(Suppl 3): 913-917.

20. Alhamdani YF, Rizk HA, Algethami MR, et al. Negative Appendectomy Rate and Risk Factors That Influence Improper Diagnosis at King Abdulaziz University Hospital. Mater Sociomed. 2018 Oct; 30 (3):215-220. doi: 10.5455/msm.2018.30.215-220.

\section{How to cite this article?}

Navya Narayanan O, Siyad P, John A. E. Histopathological correlation of resected appendicectomy specimens - a five year study in a tertiary care centre in Kerala. Trop J Path Micro 2019;5(5):287-292.doi:10.17511/jopm.2019.i05.06. 